\title{
Os benefícios eventuais previstos na Loas: o que são e como estão
}

\author{
The benefits provided for in any LOAS: \\ what they are and how they are
}

\author{
Gisele Aparecida Bovolenta*
}

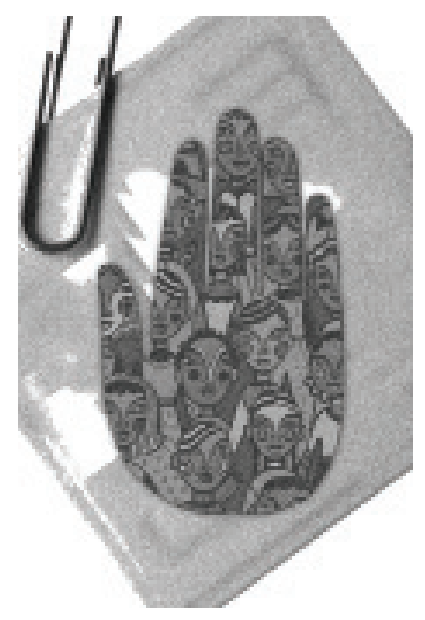

Resumo: O objetivo deste artigo é apresentar o histórico e atual contexto dos benefícios eventuais, instituídos em 1954 pela política previdenciária, como auxílio natalidade e auxílio funeral e ampliados a partir da Loas. Sua regulamentação procede da gestão municipal e estadual da política de assistência social, e esse translado, de uma política para outra, não garantiu a continuidade de concessão desse direito, pois estar legalmente instituído não foi (e não é) suficiente para estar devidamente implementado em todo o país, o que supõe empecilhos econômicos, políticos, sociais, culturais e mesmo pessoais.

Palavras-chave: Benefícios eventuais. Regulamentação. Loas. Direito.

\begin{abstract}
The aim of this paper is to present the historical context of current and potential benefits, imposed in 1954 for social security policy, such as birth assistance and funeral assistance and extended from the Loas. Its regulation comes from the municipal and state policy of social assistance and transfer it from one policy to another, didn't ensure the continuity of this entitlement, it was not to be legally established (and isn't) enough to be properly implemented in all the country, which means setbacks economic, political, social, cultural and even personal.
\end{abstract}

Keywords: Potential benefits. Regulation. Loas. Law.

* Docente de Serviço Social, Mestrado em Serviço Social pela Pontifícia Universidade Católica de São Paulo _ PUC-SP, Brasil. E-mail: gibovolenta@yahoo.com.br. 


\section{I - Introdução}

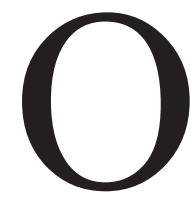

s benefícios eventuais constituem um direito social legalmente assegurado aos cidadãos brasileiros no âmbito da proteção social básica, conforme preconiza o Sistema Único de Assistência Social (Suas). Previstos desde 1993 pela Lei Orgânica de Assistência Social (Loas), se inscrevem no rol de provisão procedente da gestão municipal e estadual da política de assistência social, cuja responsabilidade de sua regulação ficaram a cargo dos respectivos conselhos. Foi destacado como objeto de regulamentação e provisão o auxílio-natalidade e o auxílio-funeral, instituídos desde 1954 pela política previdenciária e ampliados a partir da Loas às demais atenções oriundas das situações de vulnerabilidade social e calamidade pública.

É sabido que a concessão de auxílios e benefícios é uma prática inerente de atenção por parte da assistência social, a qual se construiu no campo do direito. A concessão do auxílio-natalidade, auxílio-funeral e da Renda Mensal Vitalícia (RMV) estavam até 1993 sob responsabilidade da política previdenciária. O translado de uma política para outra gerou alguns impasses em relação à categoria dos benefícios eventuais (o auxílio-natalidade e auxílio-funeral), os quais, na divisão de responsabilidades — conforme preconiza a própria Constituição Federal —, pertenceriam às esferas municipais, estaduais e do Distrito Federal. Assim, tão logo foram transferidos, deixaram de ser concedidos; o enquadramento dado à atenção limitou-se a $1 / 4$ do salário mínimo, focalizando o direito a um público bem específico - àqueles extremamente pobres. Além disso, o que deveria ser um avanço, o fato de a regulação ocorrer a partir do município, estados federados e Distrito Federal, tornou-se um problema, face às diversas limitações existentes. Com isto, somente a RMV, que ficou sob responsabilidade da União, conseguiu, a partir de 1996, ser regulamentada na assistência social e passou a prestar atenção similar por meio do Benefício de Prestação Continuada (BPC), compondo a outra categoria de benefícios assegurados na Loas: os benefícios continuados.

Em outras palavras, as legislações precedentes dividiram as tarefas: os benefícios continuados ficaram sob responsabilidade da União; os benefícios eventuais (no caso os auxílios-natalidade, funeral e demais provisões) ficaram a cargo dos estados, municípios e Distrito Federal, o que permanece sem regu- 
lação na maioria dos municípios até os dias atuais. Ao que parece, trata-se de uma parte da Loas deixada à margem da política pública de assistência social.

Esta análise, a fim de contribuir para o debate acerca da condição na qual se encontram os benefícios eventuais, se divide em três partes: os benefícios antes da Lei Orgânica da Assistência Social (Loas); os benefícios no contexto da Loas; e, por fim, os benefícios posterior à Lei Orgânica. A intenção, neste caso, é de mapear o caminho e o movimento misto pelo qual esses benefícios passaram, da previdência social para a assistência social e a situação em que se encontram atualmente.

\section{II - Os auxílios-natalidade e funeral antes da Lei Orgânica da Assistência Social}

Os benefícios eventuais por morte e natalidade, descritos hoje no artigo 22 da Loas, já percorreram uma importante trajetória até se configurarem como benefícios socioassistenciais no âmbito da política pública de assistência social.

Ao serem instituídos, por meio do Decreto n. 35.448 , de 1/5/1954, ${ }^{1}$ sob a égide da política previdenciária, foram intitulados, primeiramente, como "auxílio-maternidade" e "auxílio-funeral". Nesse momento, estavam subordinados ao vínculo previdenciário e eram ofertados por meio do pagamento de um salário mínimo² vigente à época.

1. Trata-se de um ato administrativo oriundo do Poder Executivo, cuja finalidade é regulamentar uma dada lei, ou ainda suprir uma lacuna em virtude da falta de uma lei. Neste caso, faz-se referência ao Regulamento Geral dos Institutos de Aposentadoria e Pensões.

2. O salário mínimo passou a vigorar no Brasil na década de 1940. A Lei n. 185, de janeiro de 1936, e o Decreto-lei n. 399, de abril de 1938, regulamentaram a instituição do salário mínimo no país, e o Decreto-lei n. 2162 , de $1^{\circ}$ de maio de 1940 , fixou os valores do salário mínimo, que passaram a vigorar a partir do mesmo ano. "O salário mínimo foi a primeira medida oficial instituída no país relacionada à ideia de proteção social mínima, já veiculada em vários países estrangeiros. Tanto é que o Brasil foi o $12^{\circ}$ país do mundo embora um dos primeiros da América Latina - a incorporar na sua Constituição (a de 1934) um dispositivo que previa o direito de todo trabalhador a receber um salário não inferior a certo valor. Para definir esse valor, Comissões de Salário Mínimo foram instituídas pela Lei n. 185, de 14 de janeiro de 1936, regulamentada pelo Decreto-lei n. 399, de 30 de abril de 1938, com o objetivo de realizar estudos a respeito das "necessidades normais" do trabalhador, dos quais resultou o seguinte conceito de salário mínimo: "É a remuneração mínima devida a todo trabalhador adulto, sem distinção de sexo, por dia normal de serviço e capaz de satisfazer, em determinada época, na região do país, as suas necessidades normais de alimentação, habitação, 
Promulgado pelo então presidente — Getúlio Vargas ${ }^{3}$ —, esse documento era considerado de grande relevância, devendo ser estudado e também apreciado pelo Poder Legislativo da época, uma vez que se via necessário uniformizar o sistema previdenciário existente naquele momento. Com isto, esse decreto descrevia quem eram os beneficiários; quem estava excluído desse regulamento; quem eram os segurados facultativos; quem eram os dependentes; como deveria ocorrer a inscrição no Instituto e quais eram as prestações destinadas. A única exigência, no caso, era o fato de estar vinculado a algum Instituto e ter cumprido o período de carência de doze meses.

Esses auxílios permaneceram até a década de 1960 com essa formatação. Quando ocorreu a instituição da Lei Orgânica da Previdência Social (Lops), promulgada em 26/1/1960 (Lei n. 3.807), voltou-se a fazer referência ao auxílio-maternidade e ao auxílio-funeral, propondo algumas mudanças.

O auxílio-maternidade passou, a partir de então, a ser chamado auxílio-natalidade (terminologia utilizada até os dias atuais). A legislação não trouxe apenas a mudança de nomenclatura, mas ampliou o acesso, quando passou a considerar outros dependentes do segurado. A partir da Lops, tinha direito a este auxílio, além da esposa do segurado, a filha ou a irmã, maior de idade, solteira, viúva ou desquitada, ou ainda alguém designada pelo beneficiário, desde que essa pessoa estivesse sob sua dependência econômica. A exigência estabelecida era de que houvesse no mínimo doze contribuições ao seguro social da pessoa designada, além de sua inscrição no regime previdenciário de no mínimo trezentos dias antes do parto.

A Lops também instituiu mudanças em relação ao auxílio-funeral, que passou de um para dois salários mínimos, sendo destinados aos dependentes do segurado falecido ou a quem executasse o funeral, desde que comprovadas as despesas.

\footnotetext{
vestuário, higiene e transporte". Tal medida, contudo, apesar de parecer avançada [...] continha as seguintes restrições: referiam-se às necessidades individuais do trabalhador, não incluindo a família; deixava de lado necessidades sociais, como a educação e o lazer; estabelecia níveis distintos de salário em diferentes regiões; e os estudos realizados pelas Comissões não procuraram conhecer os custos dos bens e serviços essenciais, mas os níveis salariais mais baixos existentes no país, para tomá-los como referência do salário mínimo" (Retratos do Brasil, 1984, apud Pereira, 2002a, p. 131).

3. Getúlio Vargas governou o Brasil por quinze anos ininterruptos: de 1930-45 e posteriormente, por meio do voto direto permaneceu à frente do país por mais três anos: 1951-54, quando se suicidou.
} 
O horizonte da Lops, além de organizar e orientar a Previdência Social no país, era, também, unificar os diversos Institutos de Aposentadorias e Pensões (IAPs) existentes desde 1930, de modo que passasse a existir uma legislação única que os orientasse, pois até o momento cada IAP funcionava conforme suas determinações específicas. Em outras palavras, a Lops propunha padronizar os benefícios previdenciários concedidos. No entanto, a unificação desses Institutos só ocorreu, de fato, em 1966, ou seja, seis anos após a promulgação da Lops. Por meio do Decreto-lei n. 72, de 21 de novembro de 1966, estabeleceu-se o Instituto Nacional de Previdência Social - INPS — o qual passou a coordenar e administrar os institutos então existentes de modo unificado. Além disto, a Lops imprimiu um contexto de ampliação ao acesso desses benefícios, pautado na perspectiva da universalidade, embora orientado pela lógica do seguro social, e tendo o salário mínimo como base e referência.

Tratava-se, portanto, esse rol de medidas introduzidas na Lops, de relativos avanços no esquema de proteção social brasileiro que não obstante ancorado na tradição contratual do seguro social, guiava-se pelo princípio da universalidade, no âmbito do sistema, e inaugurava a extensão ou o alargamento do leque de dependentes beneficiários, assim como do valor do pagamento dos auxílios, que tinha como parâmetro básico o salário mínimo. (Pereira, 2002a, p. 120)

Não houve, na sequência, mudanças significativas referentes à concessão desses auxílios com a Lei n. 5.890, de 8 de junho de 1973, que alterava a legislação previdenciária e dava outras providências. Os auxílios-natalidade e funeral foram, por mais de duas décadas, executados desta forma: acessado por meio do vínculo previdenciário, garantido por meio das condições aqui apresentadas.

No entanto, aos desprovidos do seguro social, não havia (legalmente) benefícios instituídos. No mais das vezes, a Legião Brasileira de Assistência (LBA) e alguns órgãos de cunho assistencial prestavam ou forneciam algum tipo de benefício (tipo eventual) dada à situação apresentada. Era comum (e talvez ainda seja), por exemplo, o fornecimento do enxovalzinho do bebê às gestantes tidas como carentes. Do mesmo modo, ocorria o fornecimento de caixão ao falecido, cuja família não possuísse meios de arcar com o ônus do funeral, entre outros auxílios categorizados em natalidade ou morte, além de tantos outros ofertados face à situação vulnerável, destinados diretamente à grande maioria da população, fora do sistema previdenciário. 
Com isto, a Previdência Social ministrava seus benefícios, entre eles os auxílios-natalidade e funeral aos seus segurados e dependentes, ficando os demais à mercê de auxílios eventualmente fornecidos, quer seja pelo órgão público (quando disponível), quer seja pela rede de solidariedade, formada por entidades, pessoas físicas, órgãos religiosos etc.

No entanto, com base na ideologia neoliberal, as políticas sociais passaram a sofrer um novo direcionamento em sua área de atuação, principalmente em suas prioridades, o que ocorreu a partir dos anos 1990. Em linhas gerais, isso se deu com cortes do gasto social, além da mencionada desativação direta dos programas sociais. Por último, mas não menos importante, à efetiva redução do papel do Estado no campo social, uma vez que, "na base de tal 'redirecionamento' estava a vontade de quebrar a espinha dorsal dos sindicatos e dos movimentos organizados da sociedade" (Draibe, 1993, p. 92).

Isto gera alterações nas provisões sociais existentes: nos benefícios sociais, juntamente nos programas sociais em geral e mesmo no sistema de seguro social, no que tange à redução em seu caráter de universalidade e seu enfoque específico de desenvolvimento, tendo essa responsabilidade sido transferida, quando necessário e/ou possível, à iniciativa privada e à sociedade civil. Fazia-se necessário, a mando do sistema econômico e da "nova" ideologia política em vigor, reformar o sistema de proteção social existente, em que a privatização, a descentralização e a focalização das atenções eram o pano de fundo de tal reforma.

Em relação à política previdenciária existente, especificamente o auxílio-natalidade e o auxílio-funeral, a Lei n. 8.213, de 24/7/1991, que descrevia os "Planos de Benefícios da Previdência Social", introduziu dentro do seguro social existente o princípio da seletividade e/ou corte de renda para acessar seus benefícios. A partir desse momento, esses auxílios foram destinados aos segurados que recebiam até três salários mínimos vigentes na época.

Em 1991, o salário-mínimo vigente era de Cr\$17.000,00 (dezessete mil cruzeiros). As mudanças trazidas pela lei de benefícios da Previdência Social apontavam que somente quem tinha menos de três salários mínimos, isto é, até Cr\$ 51.000,00 (cinquenta e um mil cruzeiros) da época, teria direito ao auxílio-natalidade. A partir daí introduziu-se, dentro de um sistema universal, princípios de seletividade. Houve também um achatamento do valor concedido, passando de um salário mínimo para a cota única (mesmo que o pai e a mãe do 
recém-nascido fossem assegurados) de 5 mil cruzeiros, o que equivalia a 29,41\% do salário mínimo da época. Ou seja, o valor desse benefício passou a ser menor que a metade do salário mínimo existente.

Em relação ao auxílio-funeral não foi diferente; prevalecia, do mesmo modo, a referência de até três salários mínimos, e a redução do valor do benefício, que passou de dois salários para apenas um salário mínimo vigente.

Havia, nessa época, o entendimento de que se tratava de benefícios em transição, que iriam passar para esfera da política de assistência social assim que possível. Tanto que, na Lei n. 8.213/1991 esses auxílios se encontravam nas disposições finais e transitórias, e não no artigo 18 , junto às demais prestações disponíveis aos segurados e dependentes. Ou seja,

a provisão desses auxílios passou a sofrer restrição à medida que foi se tornando claro que eles transitariam do âmbito da Previdência para o da Assistência. Já durante o processo de regulamentação dos arts. 203 e 204 da Constituição Federal (que tratam da Assistência Social), a Previdência foi antecipando cortes na provisão desses auxílios e focalizando sua oferta. (Pereira, 2002b, p. 120)

Os auxílios-natalidade e funeral mantiveram-se desse modo (seletivos dentre os segurados previdenciários) até deixar de ser operacionalizados, de fato, pela Previdência Social, o que ocorreu ainda na década de 1990, quando a recém-reconhecida política pública de assistência social passa a referenciá-los no corpo de sua legislação.

\section{III — Os benefícios eventuais e a Lei Orgânica da Assistência Social}

Com a promulgação da Loas, ${ }^{4}$ em 1993, os auxílios-natalidade, funeral e Renda Mensal Vitalícia (RMV) passaram a compor o rol de benefícios socioassistenciais, sob a denominação de benefícios eventuais e benefícios continuados. Não se trata apenas de uma mudança de nomenclatura, mas sim e também

4. A Lei Orgânica da Assistência Social (Loas) foi promulgada em 7 de dezembro de 1993 (cinco anos após a Constituição Federal). No entanto, vale destacar que em 1990, o então presidente da República Fernando Collor de Mello - vetou totalmente a primeira versão dessa lei, alegando que sua formatação prejudicaria o orçamento público. 
da desconstrução e redução que essas provisões sofreram ao migrar para a assistência social. Todavia, vale destacar que os benefícios eventuais foram ao mesmo tempo integrados na condição de benefícios destinados a outras eventualidades, o que ampliou suas possibilidades de atenção.

Face à Loas, a Previdência Social (sem justificativas ou argumentos) deixou, simplesmente, de conceder o auxílio-natalidade e auxílio-funeral para o qual o trabalhador formal contribuiu e que vinha sendo reduzido desde 1991 pelo corte salarial. Do mesmo modo, até hoje eles não foram devidamente fixados no campo da assistência social, isto é, foram transferidos e tornaram-se por vezes esquecidos no conjunto dos municípios brasileiros. Sua trajetória mostra que são benefícios construídos historicamente e legalmente constituídos em legislações, destinados a priori à categoria formal de trabalho e ampliados a posteriori pela Lei Orgânica da Assistência Social aos usuários e/ou público-alvo dessa política pública.

Os benefícios eventuais se apresentam no artigo 22 da Loas, fazendo referência aos auxílios por natalidade e morte, como se observa:

Art. 22 Entende-se por benefícios eventuais aqueles que visam ao pagamento de auxílio por natalidade ou morte às famílias cuja renda mensal per capita seja inferior $1 / 4$ (um quarto) do salário mínimo.

$\S 1^{\circ} \mathrm{A}$ concessão e o valor dos benefícios de que trata este artigo serão regulamentados pelos Conselhos de Assistência Social dos Estados, do Distrito Federal e dos Municípios, mediante critérios e prazos definidos pelo Conselho Nacional de Assistência Social — CNAS.

$\S 2^{\circ}$ Poderão ser estabelecidos outros benefícios eventuais para atender necessidades advindas de situações de vulnerabilidade temporária, com prioridade para criança, a família, o idoso, a pessoa portadora de deficiência, a gestante, a nutriz e nos casos de calamidade pública.

$\S 3^{\circ} \mathrm{O}$ Conselho Nacional de Assistência Social — CNAS, ouvidas as respectivas representações de Estados e Municípios dele participantes, poderá propor, na medida das disponibilidades orçamentárias das três esferas de governo, a instituição de $25 \%$ (vinte e cinco por cento) do salário mínimo para cada criança de até 6 (seis) anos de idade, nos termos da renda mensal familiar estabelecida no caput. (Brasil, 1993)

De acordo com Pereira (2010), a Lei Orgânica, em seu artigo 22, prevê três tipos de benefícios eventuais: os compulsórios, sendo estes os auxílios-na- 
talidade e funeral destinados às famílias com renda per capita de até um quarto do salário mínimo; os benefícios de caráter facultativo, instituídos conforme as necessidades oriundas das situações de vulnerabilidade social e calamidade pública; e os chamados benefícios subsidiários, descritos no $\S 3^{\circ}$ do art. 22 , como provisão às crianças de até seis anos de idade. Destes, Pereira (2010) aponta que somente os benefícios subsidiários não deveriam compor o campo de atenção por parte dos benefícios eventuais. Na realidade, enquadravam-se (e enquadram-se) muito mais na atenção continuada, conforme previa o primeiro Projeto de $\mathrm{Lei}^{5}$ que norteou a elaboração da Loas, o qual entendia a criança em processo contínuo de desenvolvimento.

A concessão desses auxílios pela assistência social se deu, a partir de então, pelo corte de renda "até 1/4 do salário mínimo", o que, de início, reconhece-se como uma perda para a sociedade na garantia e acesso aos seus direitos, pois no aparato previdenciário esses benefícios se destinavam ao conjunto de segurados, tendo sido, num segundo momento, destinados a um grupo específico de beneficiários. Essa focalização precisamente posta na Loas limitou o acesso e dificultou a regulamentação dos benefícios, conforme acrescenta Pereira (2010, p. 18), pois,

Induziu, automaticamente, a focalização desses benefícios na pobreza extrema - ao contrário do que acontecia quando integravam a Previdência - ratificando, assim, a ideia equivocada de que a assistência social tem estreita relação com a indigência. Por isso, não é de estranhar o progressivo rebaixamento do valor dos benefícios por natalidade e morte e de sua focalização na pobreza extrema, tão logo foi anunciado que eles sairiam da esfera da Previdência para integrar a da Assistência Social. E mais: que deixariam de ser contributivos para ser distributivos.

De fato a Loas amplia esses auxílios, não os tratando somente como auxílio-natalidade e como auxílio-funeral, o que ocorria quando estes se encontravam sob responsabilidade da política previdenciária. É garantido em lei que outros benefícios eventuais possam ser estabelecidos se advindos de situações de vulnerabilidade ou em casos de calamidade pública. Ao que parece, há cer-

5. Trata-se do PL n. 3.099/89 de autoria do deputado Raimundo Bezerra, cuja matriz foi, na realidade, elaborada pelo Neppos/UnB e Ipea. 
ta dificuldade na conceituação — do que seja, a que e a quem atenda — desses novos contextos reconhecidos.

A Loas reconhece dois benefícios (ambos oriundos da política previdenciária e categorizados em eventuais e continuados): os eventuais (artigo 22) e o Benefício de Prestação Continuada - BPC, (artigo 20), de modo que este último refere-se ao reconhecimento constitucional do artigo $203 \mathrm{em}$ seu quinto item da Carta Magna, que prevê: “[...] a garantia de um salário mínimo de benefício mensal à pessoa portadora de deficiência e ao idoso que comprovem não possuir meios de prover à própria manutenção ou de tê-la provida por sua família, conforme dispuser a lei” (Brasil, 1988).

O BPC foi regulamentado pelo Decreto n. 1744, de 8 de dezembro de 1995, tendo entrado em vigor em 1/1/1996, momento em que a RMV deixou de ser operacionalizada, isto é, a assistência social passa, a partir dessa data, a responder pela concessão desse benefício e a Previdência Social deixa de provê-los. Os auxílios-natalidade e funeral também foram suspensos, mas não foram devidamente regulamentados como a RMV. O artigo 39 do referido Decreto coloca que: "A partir de $1^{\circ}$ de janeiro de 1996, ficam extintos o auxílio-natalidade, o auxílio-funeral e a renda mensal vitalícia". Na realidade, os três benefícios foram transferidos da Previdência Social para a assistência social, mas somente a Renda Mensal Vitalícia foi devidamente regulamentada.

Os benefícios eventuais e o Benefício de Prestação Continuada compõem, assim, o escopo de provisão à atenção básica, afiançados na Loas em benefícios socioassistenciais. No entanto, são distintos, pois "apresentam substanciais diferenças normativas, institucionais, de financiamento e de competência estatal" (Pereira, 2010, p. 12). Além disto, "a provisão isolada do BPC, como vem ocorrendo, sem a coadjuvância dos benefícios eventuais e sem a relação otimizadora com os serviços, programas e projetos de assistência, torna-se frágil e insuficiente como medida de atenção à pobreza" (Pereira, 2002b, p. 1114).

A Constituição Federal de 1988, após 24 anos de regime militar, foi promulgada como o documento à liberdade, à democracia e à justiça social, conforme declarou Ulysses Guimarães, relator desse documento. Por isso, pautou-se em princípios como a descentralização político-administrativa e participação da sociedade brasileira, dividindo responsabilidade e reconhecendo as competências dos entes federados: município, estado, União e Distrito Federal. Assim, a partir da $\mathrm{CF} / 88$, foi reconhecida a autonomia de cada esfera pública 
no cumprimento dos preceitos legais, após um período de 24 anos de centralização na esfera federal. É possível, conforme defende Pereira (2010), que seja em virtude dessa descentralização que os benefícios eventuais ficaram a cargo dos municípios, dos estados e do Distrito Federal, enquanto o BPC, antiga RMV, ficou sob incumbência da União, pois entende-se tratar de provisão que, pelo caráter eventual e dada sua urgência e emergência de atenção, estariam mais próximos do cotidiano dos cidadãos brasileiros e justamente por isso deveriam estar regulados, pois "não se trata mais de praticar a caridade diante dos infortúnios ou calamidades sofridos [...], mas de prever e programar respostas políticas consistentes para fazer frente, como dever de cidadania, a esses acontecimentos" (Pereira, 2010, p. 14).

O mesmo deveria ter ocorrido com os benefícios eventuais também presentes no corpo da Loas, posterior regulamentação em território nacional e continuidade de atenção no acesso a esses benefícios, de modo a não prejudicar ou cessar a atenção, principalmente durante a transição de uma política para outra, conforme prevê o inciso $1^{\circ}$ do artigo 40 da Loas: "A transferência dos beneficiários do sistema previdenciário para a assistência social deve ser estabelecida de forma que o atendimento à população não sofra solução de continuidade" (Brasil, 1993). Face a isso, Pereira (2010, p. 18) acrescenta que:

Contra todas as prescrições éticas e preceituações legais relacionadas à matéria, a distribuição desses benefícios foi sustada sem nenhuma explicação, comoção social ou aplicação de penalidades. Simplesmente, a política de Previdência deixou de provê-los, em 1996, tão logo o BPC foi regulamentado, e a política de Assistência - cuja atenção majoritária centrou-se neste Benefício — postergou-se de forma injustificada a sua regulamentação para a devida operacionalização. Enquanto isso, vários cidadãos antes contemplados com os auxílios-natalidade e funeral da Previdência Social foram excluídos do seu acesso; e, outros tantos, que deveriam ser contemplados com esses e outros auxílios eventuais, no contexto da Assistência Social, estão sendo, por mais de uma década, lesados em seus direitos e desasistidos em suas legítimas necessidades.

Ou seja, não deveria ter havido cortes na atenção durante o translado de uma política para outra, o que na realidade ocorreu, nem os cidadãos no campo previdenciário poderiam ter sido penalizados como foram. Fato é que tais benefícios deixaram simplesmente de ser ofertados junto ao sistema previdenciário e se soma a isso que, ao irem para a assistência social, não foram qualifi- 
cados, formatados e implementados, mas sim esquecidos e tratados à margem da Loas. Quando muito são operacionalizados ao acaso, sem nenhum tipo de regulação que os implementasse de fato.

\section{IV - Os benefícios eventuais posteriores à Lei Orgânica da Assistência Social}

A política de assistência social avançou ao reconhecer benefícios enquanto direitos socioassistenciais. Auxílios e benefícios eram concessões presentes, porém não legitimadas. Desde 1993, quando o auxílio-natalidade e o auxílio-funeral foram trazidos para o âmbito da assistência social, sua provisão junto aos municípios tem se mostrado desregulada.

Embora não estejam explicitamente definidos na Loas, os Benefícios Eventuais constituem, na história da política social moderna, a distribuição pública de provisões materiais ou financeiras a grupos específicos que não podem, com recursos próprios, satisfazerem suas necessidades básicas. Trata-se de um instrumento protetor diferenciado sob a responsabilidade do Estado que, nos termos da Loas, não tem um fim em si mesmo, posto que inscreve em um espectro mais amplo e duradouro de proteção social, do qual constitui a providência mais urgente. (Pereira, 2010, p. 11)

Algumas iniciativas estatais já se fizeram presente no intuito de regulamentá-los, mas a situação ainda não se concretizou plenamente no conjunto dos municípios brasileiros. Por mais de uma década esses benefícios ficaram meio esquecidos, o que contribuiu para que ainda hoje a situação irregular permaneça.

Embora antecipado por algumas iniciativas de regulamentação desses benefícios, foi, na verdade, a partir de 2006 que se deu maior visibilidade a esse assunto, promovendo alguns avanços rumo à regulamentação desse direito: em atenção ao que a Loas preconizava no artigo 22, o Conselho Nacional de Assistência Social (CNAS) editou a Resolução n. 212, em 19 de outubro daquele ano e, no ano seguinte, o governo federal instituiu o Decreto n. 6.307, em 14 de dezembro de 2007. Dois documentos importantes e fundamentais que merecem, aqui, ser analisados e que provavelmente serviram de base para a promoção de algumas regulações ocorridas no país a partir de então. 


\section{Quadro 1}

Síntese das principais ações a partir da Loas referente à regulação dos benefícios eventuais junto aos municípios brasileiros

\begin{tabular}{|c|c|}
\hline Ano & Ações \\
\hline 1993 & $\begin{array}{l}\text { Instituição na Loas dos auxílios-natalidade e funeral — artigo 22. Oriundos da política } \\
\text { previdenciária foram denominados de benefícios eventuais. }\end{array}$ \\
\hline 1996 & $\begin{array}{l}\text { Pesquisa realizada pelo Neppos }{ }^{7} \text { e } \text { Ceam }^{8} \text { no sentido de conhecer a atual conjuntura desses } \\
\text { benefícios no âmbito da política pública de assistência social, encomendada pelo Conselho } \\
\text { Federal de Serviço Social (CFESS), buscava auxiliar os debates ocorridos no CNAS. }\end{array}$ \\
\hline 1996 & $\begin{array}{l}\text { O CNAS elaborou um documento de trabalho a partir ao artigo } 22 \text { da Loas no sentido de } \\
\text { orientar suas discussões referente à criação de uma proposta para sua normatização. }\end{array}$ \\
\hline 1997 & $\begin{array}{l}\text { Reunião ampliada no CNAS a fim de avaliar a pesquisa realizada em } 1996 \text { e dar encaminhamen- } \\
\text { to rumo à regulação dos benefícios eventuais. }\end{array}$ \\
\hline 1997 & Elaboração da minuta de resolução pelo CNAS a fim de regulamentar esses benefícios. ${ }^{9}$ \\
\hline 1999 & $\begin{array}{l}\text { Elaboração pelo CNAS de um documento sobre as referências básicas para a concessão desses } \\
\text { benefícios, no sentido de auxiliar os municípios para sua implementação. }\end{array}$ \\
\hline 2004 & $\begin{array}{l}1^{\text {a }} \text { Pesquisa Nacional realizada pelo MDS no sentido de conhecer a implementação dos } \\
\text { benefícios eventuais. Houve a participação de } 626 \text { municípios de onze estados brasileiros. }{ }^{10}\end{array}$ \\
\hline 2004 & $\begin{array}{l}\text { Prestação de consultoria pela profa. Potyara ao Departamento de Benefícios Assistenciais do } \\
\text { MDS. }\end{array}$ \\
\hline 2006 & Elaboração pelo MDS da Minuta de Portaria, que resultou no decreto de 2007. \\
\hline 2006 & $\begin{array}{l}\text { Promulgação da Resolução n. } 212 \text { pelo CNAS, que propõe critérios orientadores para a } \\
\text { regulação da provisão dos benefícios eventuais no âmbito da política pública de assistência } \\
\text { social. }\end{array}$ \\
\hline
\end{tabular}

6. O fato de os benefícios eventuais não estarem regulados na maioria dos municípios e estados brasileiros não significa que não haja algumas iniciativas no sentido de reverter esta situação.

7. Neppos - Núcleo de Estudos e Pesquisa em Política Social - UnB, coordenado pela profa. dra. Potyara. A. P. Pereira.

8. Ceam - Centro de Estudos Avançados Multidisciplinares da UnB - diretor: Nielson de Paula Pires.

9. "Essa minuta foi submetida à apreciação da Consultoria Jurídica do Ministério da Previdência e Assistência Social, recebendo, ao mesmo tempo pareceres favoráveis e desfavoráveis. Os favoráveis diziam respeito à definição de prazos pelo CNAS para regulamentação dos benefícios eventuais no âmbito dos conselhos estaduais, municipais e do Distrito Federal; mas os desfavoráveis concerniam à determinação de prazos para o início de pagamento de tais benefícios, dada a autonomia dos entes federados neste aspecto" (Pereira, 2010, p. 21).

10. Participaram desta pesquisa os seguintes estados: Rio Grande do Sul, São Paulo, Rio de Janeiro, Pernambuco, Espírito Santo, Mato Grosso, Mato Grosso do Sul, Minas Gerais, Pará, Goiás e Maranhão. 


\begin{tabular}{|c|c|}
\hline Ano & Ações \\
\hline 2007 & $\begin{array}{l}\text { Promulgação do Decreto Presidencial n. } 6.307 \text {, que dispõe sobre os benefícios eventuais de } \\
\text { que trata o artigo } 22 \text { da Loas. }\end{array}$ \\
\hline 2009 & $\begin{array}{l}\text { Instituição da Resolução n. } 07 \text { pela CIT, que estabelece procedimentos para gestão integrada } \\
\text { dos serviços, benefícios socioassistenciais e transferências de renda. }\end{array}$ \\
\hline 2009 & $\begin{array}{l}\text { Promulgação da Resolução n. } 109 \text { do CNAS referente à tipificação dos serviços socioas- } \\
\text { sistenciais. Nesse documento, os benefícios eventuais se encontram na categoria de "serviços } \\
\text { de proteção em situação de calamidades públicas e de emergências". }\end{array}$ \\
\hline 2009 & $\begin{array}{l}2^{a} \text { Pesquisa Nacional realizada pelo MDS e CNAS sobre a implementação dos benefícios } \\
\text { eventuais, do qual resultou o "Relatório sobre o Levantamento Nacional dos Benefícios } \\
\text { Eventuais". Nessa pesquisa, buscou-se mapear a situação nacional desses benefícios, e houve } \\
\text { a participação de } 75 \% \text { dos municípios brasileiros. }\end{array}$ \\
\hline
\end{tabular}

Os documentos emitidos em âmbito federal - a Resolução n. 212/06 do CNAS e o Decreto Federal n. 6.307/07 — foram norteadores e auxiliam os municípios a regulamentar sua situação na execução e concessão de auxílios e benefícios, em geral operacionalizada ao acaso por meio dos plantões sociais. Ao que parece, o governo federal foi até onde a legislação permitia, uma vez que, por se tratar de benefícios oriundos das esferas municipais, estaduais e do Distrito Federal, a União não poderia regulamentá-los, apenas orientá-los. Isto é colocado na própria Loas quando o artigo 22 diz ser responsabilidade municipal, estadual e distrital sua gestão e execução.

Ao editar a Resolução n. 212, o CNAS reconheceu uma de suas competências (colocadas no artigo 18 da Loas) e considerou o benefício eventual como direito garantido em lei e de longo alcance social. A importância e impacto desses documentos podem ser observadas no Relatório do Levantamento Nacional realizado pelo MDS em conjunto com o CNAS, realizado em 2009, em que quase $70 \%$ dos municípios - dos 1229 que declaram ter regulamentado — o fizeram a partir de 2006, o que supõe que esses documentos tenham servido de base e orientação quanto à sua regulação.

A Loas, ao adotar diretrizes em consonância com a Constituição Federal, entende que as atribuições são descentralizadas e participativas, isto é, cada órgão federado possui suas competências e responsabilidades face à garantia da política pública. Isto avança e limita a regulamentação de um direito, caso dos benefícios eventuais. Avança por respeitar e considerar as especificidades 
locais e limita em virtude dos impasses locais de ordem econômica, política e social, entre outros, que dificultam sua execução.

No documento emitido em 2006, entendem-se os benefícios eventuais como "uma modalidade de provisão de proteção social básica de caráter suplementar e temporário que integra organicamente as garantias do Sistema Único de Assistência Social (Suas), com fundamentação nos princípios de cidadania e nos direitos sociais e humanos" (Art. 1', Resolução n. 212/2006).

Do mesmo modo, definir o que são contingências sociais dá base para determinar ou delimitar o campo de ação desse direito no âmbito da política de assistência social, isto é, deve-se prestar auxílio ao cidadão face à situação de contingência social, a qual pode levar ao risco, de modo que isto ocorra dentro da política pública de assistência social.

Etimologicamente, o termo contingência deriva do latim contingentia e traduz um fato possível, porém incerto; é a possibilidade de que algo aconteça ou não. De acordo com Houaiss (2001), significa eventualidade; já social, refere-se à sociedade, à ordem social. Com isto, presume-se que contingência social seriam as eventualidades ocorridas ou oriundas na sociedade em razão de algum fato ou acontecimento que pode vir a ocorrer (seria uma possibilidade, uma previsão).

Essa possibilidade que busca definir contingência termina por associar-se ao termo eventual. Talvez por isso buscaram-se definir, desde a Loas, os benefícios eventuais como aqueles destinados a atender ao conjunto de eventualidades, possíveis de ocorrer com qualquer cidadão. Eventual, segundo Houaiss (2001), quer dizer esporádico, ocasional, o que acontece de vez em quando, isto é, o artigo 22 da Loas trata de benefícios que eventualmente podem ocorrer na vida dos cidadãos, como, por exemplo, casos de morte e nascimento.

Alguns desses fatos ou acontecimentos, embora ocasionais no ciclo de vida familiar, são previsíveis de ocorrência. Cada município, ao elaborar sua lei referente à implementação de seus benefícios eventuais, poderia ou deveria fazer uma leitura da realidade vivenciada, a fim de estimar a incidência na população de algumas dessas contingências sociais, o que ocorreria a partir de um mapeamento local. A Resolução n. 212/06 faz jus aos auxílios-natalidade e funeral, propondo sua regulamentação, a qual tem sido postergada há tempos. Ao se referir a "contingências sociais" não se reduz aos dois benefícios. Com 
isso, os municípios podem ir além desses auxílios, podendo ofertar outros benefícios eventuais próprios à sua realidade particular.

O contexto sociopolítico do Brasil deve ser levado em conta ao se tentar entender por que esses benefícios não estão até hoje implementados em todo o país, como descreve Sérgio Buarque de Holanda em "O homem cordial” (1975), em que relações de compadrio, amizade e simpatia moldam quase todas as relações sociais num país marcado pelo legado autoritário, clientelista e patrimonialista.

Esse fator pode ter contribuído para a não regulamentação desses benefícios nos municípios brasileiros: quando não há regulação, pode-se atender quem se quer atender (ou se indica), como quiser atender (com recursos provenientes ou remanejados), pode ocorrer do modo que for mais conveniente. Além disso, é sabido que, por vezes, a assistência social constituiu-se (e ainda se constitui) introduzindo mecanismos de dependência ou de relação de troca; em outras palavras, usada por políticos descompromissados com a garantia de direitos ao cidadão. A falta de regulação dessa categoria de benefícios dá margem para que a "cordialidade", já descrita por Sérgio Buarque de Holanda, seja condutora na concessão desses benefícios, justamente por não haver clareza, transparência e especificidade de atenção.

A Resolução n. 212/06 também endossou o critério de renda nos termos da Loas, isto é, aqueles com renda per capita familiar de até 1/4 do salário mínimo. Ficou a cargo das esferas governamentais a possibilidade de ampliar esse acesso, não limitando ou focalizando o direito aos considerados extremamente pobres ou indigentes, uma vez que esses benefícios já foram reduzidos ao virem para a assistência social. No caso dos auxílios-natalidade e funeral, estes já vinham sendo focalizados desde a década de 1990, quando ainda se encontravam no campo previdenciário.

Além disto, trata-se de benefícios com regulação compartilhada entre os municípios e seus respectivos estados. Não é um ônus a mais para os municípios, como muitas vezes se interpreta, mas um direito que deverá ser partilhado. Ocorre que, no mais das vezes, os estados não se manifestam, esperando dos municípios alguma iniciativa, e estes esperam de alguém alguma “ordem". De qualquer modo, observa-se certa ausência por parte dos estados brasileiros, ao contrário do que previa o artigo 15: “O Estado definirá a sua participação no 
cofinanciamento dos benefícios eventuais junto aos seus Municípios [...]" (Brasil, 2006). Entende-se que tal iniciativa possa acontecer a partir do município, por ser o lócus mais próximo do cidadão, onde se identificam as necessidades, onde o indivíduo busca por seus direitos. Todavia, nada impede uma qualificação conjunta, mesmo porque trata-se de uma corresponsabilidade não só no financiamento, mas também na gestão e qualificação desses benefícios. Ao governo federal, por meio do CNAS, conforme prevê o inciso $1^{\circ}$ do artigo 22 , coube estabelecer prazos e critérios para que esses benefícios fossem implementados em todo o país.

Em relação a isso, a Resolução n. 212/06 estabeleceu esses prazos a fim de estimular, acelerar e fomentar a regulamentação dessa categoria de benefícios junto aos municípios brasileiros: "A regulamentação dos benefícios eventuais e a sua inclusão na lei orçamentária do Distrito Federal e dos municípios dar-se-ão no prazo de até doze meses e sua implementação até vinte e quatro meses, a contar da data da publicação dessa Resolução" (Brasil, 2006).

Esse documento foi editado em 2006, portanto os municípios teriam até 2008 - 24 meses -, como prevê a Resolução, para regularizar esses benefícios em seus municípios. No entanto, esses prazos foram simplesmente ignorados na maioria dos municípios brasileiros, e os maiores prejudicados acabaram por ser o cidadão de direito. Sobre ele recai a penalização pela morosidade ou ausência de execução dos benefícios eventuais. ${ }^{11}$

Em dezembro do ano seguinte (2007), a União lançou mão do Decreto Federal n. 6.307, que dispõe sobre os benefícios eventuais de que trata o artigo 22 da Lei n. 8.742 (Loas), de 1993, referente aos princípios, concessão, destino e as devidas competências desses benefícios perante o Suas. Assim como a Resolução, esse documento buscava fomentar o processo de regulação dos benefícios eventuais em suas devidas esferas de governo. As orientações trazidas por esses dois documentos deveriam servir de base para dar início ou continuidade, conforme o caso, ao processo de execução desses benefícios no conjunto dos municípios, estados e Distrito Federal.

11. De acordo com o Relatório sobre o Levantamento Nacional dos Benefícios Eventuais realizado pelo MDS em parceria com o CNAS em 2009, dos 4.174 municípios participantes, 2.172 (ou 52\%) relataram possuir regulação para a provisão de seus benefícios eventuais. Destes, apenas 1.229 (ou 29,4\%) relataram que tal regulação se encontra em consonância com os parâmetros legais estabelecidos. 
Tanto o decreto de 2007 quanto a resolução de 2006 já nasceram no contexto do Suas, em que a provisão desse benefício contribui no sentido de instituir uma política pública de caráter universal operacionalizada de modo coerente, sintonizado e preciso, dentro dos princípios e diretrizes construídas pelo Suas.

Ao se trabalhar a partir desses princípios e diretrizes, buscou-se superar a pulverização de ações e recursos, fortalecendo a assistência social enquanto responsabilidade estatal e como política de proteção social.

No Decreto n. 6.307/07 coube à União caracterizar os possíveis benefícios eventuais. Nesse sentido, o artigo $1^{\circ}$ estabelece que se trate de "provisões suplementares e provisórias, prestadas aos cidadãos e às famílias em virtude de nascimento, morte, situações de vulnerabilidade temporária e de calamidade pública" (Brasil, 2007). Desta forma, esses benefícios integrariam as seguranças previstas no Sistema Único da Assistência Social.

De acordo com a Política Nacional de 2004, a proteção social afiançada deve garantir segurança de sobrevivência (de rendimento e de autonomia), de modo que todo cidadão tenha uma forma monetária de assegurar sua própria sobrevivência. Sua provisão se dá pelo acesso às necessidades básicas, como alimentação, vestuário, abrigo, entre outras; segurança de acolhida, em casos de separação familiar ou ausência de qualquer tipo de vínculo, oriunda das mais diversas situações: destituição, violência, desastres ou acidentes naturais etc., e, por fim, garantia à segurança de convívio ou de vivência familiar, supondo que as pessoas vivem em grupos e necessitem manter estas relações; supõe a não aceitação da perda de relações.

Nota-se que tal definição, em consonância com a Resolução n. 212/06 e a própria Loas, busca delimitar e caracterizar o conjunto dos benefícios eventuais: casos de morte (auxílio-funeral), nascimento (auxílio-natalidade), vulnerabilidade social e calamidade pública.

É amplo, de fato, o entendimento de vulnerabilidade temporária. Segundo Houaiss (2001) vulnerável é alguém suscetível de ser ferido, ofendido etc. Portanto, os benefícios eventuais deveriam atender as situações em que houvesse perdas (privação de bens e de segurança material), danos (agravos sociais e ofensas) e risco (ameaça de sérios padecimentos) face a algum sofrimento. Esta definição complementa os preceitos da Resolução n. 212/06 e da Loas, entendendo que se trata de um campo de benefícios acionados face às emergên- 
cias eventuais que surgem no cotidiano do cidadão. Com isso, reforça o artigo 22 da Loas, quando chama os auxílios-natalidade e funeral de benefícios eventuais. Isto é, são aqueles oriundos de situações imprevisíveis, incertas, acidentais, ocasionais ou eventuais, ocorridas no cotidiano do cidadão.

Os municípios, estados e Distrito Federal ficaram com a incumbência de melhor qualificar quais seriam essas atenções. No caso, quais seriam, possivelmente, essas perdas, danos e riscos, identificadas a partir da realidade local. O Decreto n. 6.307/07 aponta genericamente, mesmo porque trata-se de benefícios oriundos da realidade do cidadão, identificados em âmbito municipal, estadual e distrital. Também ficaram a cargo dessas esferas governamentais delimitarem sua atuação referente às chamadas calamidades públicas, uma vez que há municípios que sofrem em períodos de chuvas ou de secas, e com isto poderiam descrever a atenção dada aos cidadãos diante dessas ocorrências, de modo que o acesso ao benefício se desse pela via do direito, não pela via do acaso.

Quando o Decreto n. 6.307/07 e a Resolução n. 212/06 dizem se tratar de situações suplementares e provisórias aqueles cobertos pelo benefício eventual, termina por afirmar que esses benefícios devam atender, suprir ou compensar a deficiência de alguma coisa, o que se daria de modo temporário e não definitivo: situações imprevisíveis e improváveis oriundas da ocorrência de morte, de nascimento, do estado de vulnerabilidade e, por fim, da circunstância de calamidade pública.

São questões que ficariam a cargo de cada esfera pública delimitar e conceituar, de modo a respeitar as especificidades de cada realidade, o que se daria por meio dos respectivos Conselhos de assistência social - municipal, estadual e do Distrito Federal.

Essas definições contribuem para assegurar e qualificar como direito as provisões relativas à política de assistência social. É comum a assistência social ser chamada para estar presente face aos mais diversos fatos e questões. No caso, parece que cabe a ela atender um pouco de tudo, isto é, a existência de eventualidade deve ser alvo de atenção, respeitando o campo de ação de cada política pública, um tipo “cada um cuida do seu”. Há, é bem verdade, eventualidade na política de saúde, política de educação, política de habitação, entre outras que precisam ser definidas e qualificadas em suas respectivas áreas de atuação, senão, ao que parece, a política de assistência social cuida do que as demais não cuidam. Isso requer um necessário, claro e preciso entendimento 
do que de fato seja incumbência da política de assistência social. O Decreto n. 6.307 faz referência a esse fato, dado a sua importância: "As provisões relativas a programas, projetos, serviços e benefícios diretamente vinculados ao campo da saúde, educação, integração nacional e das demais políticas setoriais não se incluem na modalidade de benefícios eventuais da assistência social" (Brasil, 2007). Isto delimita área, competência e responsabilidade.

Assim, as legislações e normativas instituídas até então demandaram um grande esforço para dar mais conteúdo, concretude e precisão aos benefícios eventuais, pois regulamentá-los e implementá-los no Brasil passa obrigatoriamente pela necessidade de romper com a incerteza da provisão. A perspectiva desse direito deve ser universal e estar articulada com os serviços socioassistenciais e com as demais políticas públicas.

É fato que as várias iniciativas e normatizações descritas aqui foram importantes, mas não suficientes para que os benefícios eventuais fossem realmente regulados no conjunto dos municípios brasileiros. $\mathrm{O}$ fato de ser um benefício eventual não retira a obrigatoriedade de ser e estar devidamente articulado com os serviços socioassistenciais, com outras políticas públicas e ser operacionalizado a partir dos princípios e diretrizes do Suas. Tal perspectiva normatizadora parece colocar-se em contraponto a um benefício executado historicamente de forma fragmentada e dissociado dos princípios de uma política de proteção social não contributiva. Aqui reside a necessidade de se fazer entender que ocorrências de contingências sociais, vulnerabilidades sociais e calamidades públicas merecem respostas e atenção na perspectiva do direito e na universalidade do acesso, sendo devidamente qualificadas.

\section{V-Conclusão}

Há, de fato, desafios na consolidação dos princípios e diretrizes trazidos pelo Suas. O Brasil é um país que histórica e culturalmente reproduziu uma assistência social à margem de outras políticas para minimizar os impactos da questão social. Quebrar esse paradigma e construir uma política de direito é por si só um desafio, principalmente se levarmos em conta o fato de se tratar de um país com uma das maiores concentrações de renda e uma das maiores desigualdades sociais do mundo. 
Além disso, temos também o desafio de dissolver modelos e práticas ainda existentes na sociedade, que insistem em operar uma assistência social de caráter compensatório e provisório, tanto por parte de gestores, quanto de profissionais, intelectuais e mesmo usuários, que não veem a assistência social na perspectiva do direito. Prova disso é a significativa presença de primeiras-damas, Fundo Social de Solidariedade (no caso do estado de São Paulo), órgãos ligados ao Estado, como o Comunidade Solidária, que operam no slogan da ajuda e do voluntariado desconexos ao status de direito, isso sem falar das diversas campanhas nacionais que chamam a sociedade a "fazer a sua parte" como, por exemplo, "Criança Esperança", "Tele Tom", entre outras, e, principalmente no meio empresarial, a ideologia da "responsabilidade social".

Existe, enfim, na sociedade, um conjunto de condições contrárias à emancipação e consolidação da assistência social enquanto política pública de direito. $\mathrm{O}$ fato de os benefícios eventuais não terem sido plenamente regulamentados até os dias de hoje demonstra um dever estatal parcialmente realizado, isto é, um direito posto, hoje, numa condição marginal.

Ademais, do ponto de vista da gestão das políticas públicas, a não regulamentação dos BEs caracteriza um procedimento politicamente incorreto e traiçoeiro, conhecido como ação não governamental, porque, paradoxalmente, produz efeitos sociais mais danosos do que qualquer tentativa de intervenção pública. Isso porque a não ação, por ser aparentemente inexistente, não é identificada, controlada e avaliada e, por isso, dá margem ao surgimento de ações improvisadas, intuitivas, quando não inconsequentes ou até oportunistas. (Pereira, 2010, p. 17)

Os diversos limites no processo de regulamentação desse direito incentivou em vários municípios, segundo Pereira (2010, p. 19) a:

práticas assistencialistas e clientelistas em torno de demandas eventuais, já que, para a satisfação dessas demandas, não existiam normas-padrão regulamentadas e compatíveis com o conteúdo da Loas e da PNAS-Suas. Em decorrência, não é casual que a prática da concessão dos Benefícios Eventuais venha apresentando as seguintes tendências: cada governo municipal os concebem, denominam, proveem e administram, de acordo com o seu entendimento, valendo-se quase sempre do senso comum para, dentro de suas possibilidades financeiras e gerenciais, atender contingências sociais prementes. Tem-se, assim, num espaço não desprezível de participação da Assistência Social como política pública e direito de ci- 
dadania a condenável prática do assistencialismo que, além de desafiar os recentes avanços no campo assistencial, vem se afirmando como um não direito social.

Ou seja, urge a necessidade de trazer essa temática ao centro dos debates acadêmicos e profissionais, cujo intuito seja compreender e melhor qualificar essa categoria de benefícios socioassistenciais tratados à margem da Loas e das legislações subsequentes, no sentido de caminhar rumo à sua plena regulamentação, entendida como o fortalecimento do Suas e acesso a política pública de assistência social na perspectiva do direito.

Recebido em jan./2011 n Aprovado em abr./2011

\section{Referências bibliográficas}

BRASIL. Decreto n. 35.448, de $1^{\circ}$ de maio de 1954. Senado Federal, Brasília, 2010. Disponível em: <http://www.senado.gov.br/legislacao/listapublicacoes $>$. Acesso em: 16 fev. 2010.

. Decreto n. 36.132, de 3 de setembro de 1954. Senado Federal, Brasília, 2010. Disponível em: $<$ http://www.senado.gov.br/legislacao/ListaPublicacoes $>$. Acesso em: 16 fev. 2010.

. Decreto n. 36.222, de 24 de setembro de 1954. Senado Federal, Brasília, 2010. Disponível em: $<$ http://www.senado.gov.br/legislacao/ListaPublicacoes $>$. Acesso em: 16 fev. 2010.

. Lei n. 3.807, de 26 de agosto de 1960. Presidência da República, Brasília, 2010. Disponível em: <http.//www.planalto.gov.br/ccvil_03/Leis/1950-1969/L3807.htm>. Acesso em: 16 fev. 2010.

. Lei n. 5.890, de 8 de junho de 1973. Presidência da República, Brasília, 2010. Disponível em: $<$ http://www.planalto.gov.br/ccivil_03/leis/15890.tml $>$. Acesso em: 16 fev. 2010.

Constituição da República Federativa do Brasil. Brasília: Centro Gráfico do Senado Federal, 1988.

. Lei n. 8.213, de 24 de julho de 1991. Presidência da República, Brasília, 2010. Disponível em: <http://www.planalto.gov.br/ccivil_03/leis/18213cons.htm>. Acesso em: 16 fev. 2010. 
BRASIL. Presidência da República. Lei Orgânica da Assistência Social, n. 8.742, de 7 de setembro de 1993.

. Ministério do Desenvolvimento Social e Combate à Fome. Política Nacional de Assistência Social. Brasília: PNAS, 2004.

. Ministério do Desenvolvimento Social e Combate à Fome. Histórico dos beneficios eventuais. Brasília, 2008. Disponível em: <http://www.mds.gov.br/suas/revisoes_bpc/benefícios-eventuais/historico-dos-beneficios-eventuais $>$. Acesso em: 15 ago. 2008.

. Ministério do Desenvolvimento Social e Combate à Fome. Resolução n. 109, de 11de novembro de 2009. Brasília: MDS, 2009.

. Conselho Nacional de Assistência Social. Resolução CNAS n. 212, de 19 de outubro de 2006.

de 2007.

Presidência da República. Decreto Presidencial n. 6.307, de 14 de dezembro

CONSELHO REGIONAL DE SERVIÇO SOCIAL DO ESTADO DE SÃO PAULO. Legislação brasileira para o Serviço Social: coletânea de leis, decretos e regulamentos para a instrumentação do A. S. São Paulo, 2004.

DRAIBE, Sônia Miriam. As políticas sociais. Revista USP, São Paulo, n. 17, p. 87-101, 1993.

HOLANDA, Sérgio Buarque de. Raizes do Brasil. 8. ed. Rio de Janeiro: Olympio Editora, 1975.

HOUAISS, Antonio. Dicionário Houaiss da língua portuguesa. Rio de Janeiro: Objetiva, 2001.

PEREIRA, Potyara Amazoneida. Panorama do processo de regulamentação e operacionalização dos benefícios eventuais regidos pelas Loas. Cadernos de Estudos Desenvolvimento Social em Debate, Brasília, n. 12, 2010.

. Necessidades humanas: subsídios à crítica dos mínimos sociais. 2. ed. São Paulo: Cortez, 2002a.

; NASSER, I. R.; CAMPOS, S. M. A. Os percalços dos benefícios eventuais regidos pela Loas. Cadernos do Ceam. Núcleo de Estudos e Pesquisa em Política Social, Brasília, ano III, n. 11, p. 113-135, 2002b. 